Document downloaded from:

http://hdl.handle.net/10251/56922

This paper must be cited as:

Carrillo Abad, J.; García Gabaldón, M.; Ortega Navarro, EM.; Pérez-Herranz, V. (2012). Recovery of zinc from spent pickling solutions using an electrochemical reactor in presence and absence of an anion-exchange membrane: Galvanostatic operation. Separation and Purification Technology. 98:366-374. doi:10.1016/j.seppur.2012.08.006.

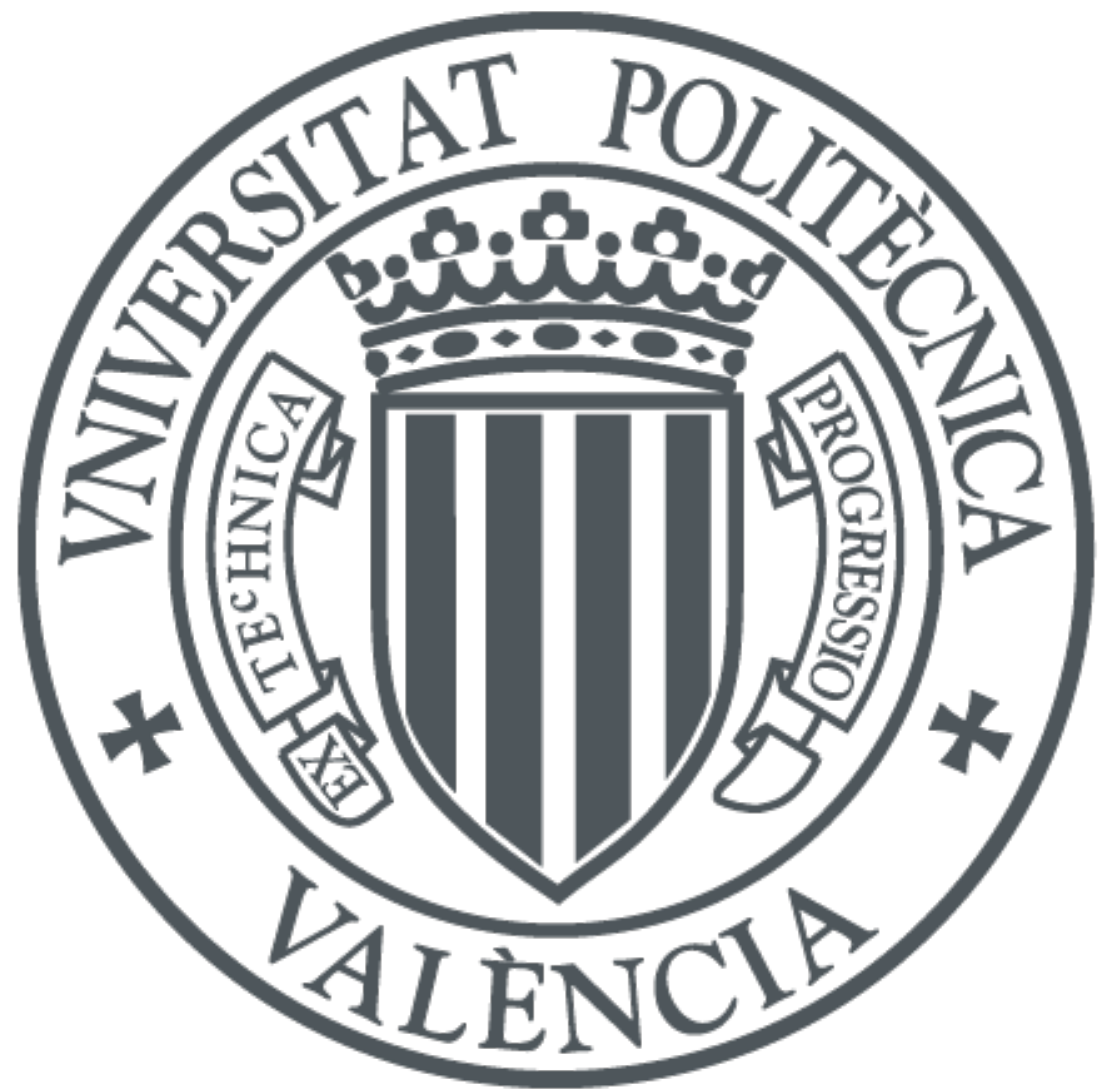

The final publication is available at

http://dx.doi.org/10.1016/j.seppur.2012.08.006

Copyright Elsevier

Additional Information 


\title{
RECOVERY OF ZINC FROM SPENT PICKLING SOLUTIONS \\ USING AN ELECTROCHEMICAL REACTOR IN PRESENCE AND \\ ABSENCE OF AN ANION-EXCHANGE MEMBRANE.
}

GALVANOSTATIC OPERATION.

\author{
J. Carrillo-Abad, M. García-Gabaldón, E. Ortega, V. Pérez-Herranz* \\ Grupo IEC, Departamento de Ingeniería Química y Nuclear, Universitat Politècnica de \\ València (UPV), Camino de Vera s/n, 46900 Valencia, Spain.
}

*Corresponding author. Tel.: +34-6-3876320; fax: +34-6-3877639; E-mail address:

vperez@iqn.upv.es (V. Pérez-Herranz)

Keywords: electrochemical deposition, chlorine, iron, redissolution, pickling solutions, zinc electrodeposition

\begin{abstract}
The performance of a one and two-compartment electrochemical reactor under galvanostatic control for zinc recovery present in the spent pickling solutions is studied in this paper. These solutions, which mainly contain $\mathrm{ZnCl}_{2}$ and $\mathrm{FeCl}_{2}$ in aqueous $\mathrm{HCl}$ media, come from the hot dip galvanizing industry. The effect of the anion-exchange membrane (AEM) on the figures of merit of the electrochemical reactor is analyzed.
\end{abstract}

In the absence of iron in solution, as the current value was shifted towards more negative values, the zinc fractional conversion increased because of the increase in the 
zinc reduction rate. However, the increase in current values made current efficiency decrease due to the hydrogen-reduction side reaction, which caused an increment in the specific energy consumption. The presence of iron in synthetic solutions led to a decrease in current efficiency associated with the reverse redox $\mathrm{Fe}^{2+} / \mathrm{Fe}^{3+}$ system and to the enhancement of the HER, which also induced increments in the local $\mathrm{pH}$ and the subsequent zinc redissolution. These adverse effects related to the presence of iron could be minimized by the interposition of an AEM. In this case, the zinc redissolution was eliminated which enabled zinc conversion values close to $100 \%$ together with higher current efficiencies as the consumption of current by the system $\mathrm{Fe}^{2+} / \mathrm{Fe}^{3+}$ was diminished. 


\section{1- Introduction}

Hot dip galvanizing processes offer a simple and effective way for corrosion protection of steel parts. This protection is based on covering the steel with a thin layer of metallic zinc that protects steel from corrosion by two ways: surface coating and sacrificial anode as zinc is lees noble than iron. This process consists of the following steps: alkaline or acidic degreasing, rinsing with water, pickling with dilute hydrochloric or sulphuric acid, rinsing with water, fluxing in aqueous $\mathrm{ZnCl}_{2} / \mathrm{NH}_{4} \mathrm{Cl}$ baths, drying and dipping into molten zinc at temperatures of about $450{ }^{\circ} \mathrm{C}$ for a defined period [1].

The pickling step, previous to the galvanization process, generates a succession of effluents containing, among other substances, high concentrations of $\mathrm{ZnCl}_{2}, \mathrm{FeCl}_{2}$ and $\mathrm{HCl}$. This gives rise to an environmental problem that has to be solved due to the hazardous nature of the effluents $[2,3]$. In addition, the decrease of natural reserves of non-ferrous metals and the requirement of environmental protection make zinc electrowinning from spent pickling solutions an interesting alternative $[4,5]$. Moreover, the electrolytic recovery of zinc present in the spent pickling baths is a suitable technique because zinc electrowinning has been practiced for many years [6]. In fact, $80 \%$ of world zinc production is obtained by electrowinning [1].

In our previous paper [7], the potentiostatic recovery of zinc present in the spent pickling bath using an electrochemical reactor was studied. The major interfering reaction during zinc electrodeposition on the cathode surface was the hydrogen evolution reaction (HER), although iron presence also diminished the current efficiency. It was also observed that during the last instants of electrolysis, zinc concentration at the 
electrochemical reactor increased again due to local $\mathrm{pH}$ increases near the cathode surface.

In the potentiostatic operation, a constant potential on the working electrode with respect to the reference electrode is established, and the electrode potential determines which electron transfer reaction can occur and its absolute rate. Only species with a lower negative redox potential than the applied one will be reduced in the electrode, therefore a little amount of current is wasted. On the other hand, in the galvanostatic operation a constant current is passed through the electrochemical reactor, and the electrode potential varies with time. When the concentration of the reactant finally drops to zero a sharp rise in potential takes place until a new electrode reaction begins $[8,9]$.

The potentiostatic way of operation is easy to put into practice on a laboratory scale by using a standard potentiostat. However, its industrial application is more difficult because of the high cost of a high-power potentiostats. Another drawback of the potentiostatic mode in industrial applications is the requirement of reliable reference electrodes. Then, for most industrial electrochemical processes, constant current control is the most useful operating approach from both a practical and theoretical stand-point. [9].

The purpose of this work is to analyze the behavior of an electrochemical reactor working in galvanostatic mode for the zinc recovery present in the spent pickling baths. The use of an anion-exchange membrane (AEM) between the anodic and cathodic 
compartments has also been evaluated in order to reduce the zinc redissolution in the cathodic compartment.

\section{2- Experimental}

The undivided electrochemical reactor used in this work was adequately described in our previous paper [7] and consists of a Pyrex glass of $100 \mathrm{ml}$ with two graphite electrodes acting as working and counter electrodes and a standard $\mathrm{Ag} / \mathrm{AgCl}$ saturated $\mathrm{KCl}$ electrode acting as reference electrode.

A schematic diagram of the two-compartment electrochemical reactor is presented in Fig. 1. The two-compartment reactor containing the anionic exchange membrane is made of two Pyrex glass chambers attached by means of four screws on their sides with an IONICS AR-204-SZRA-412 anion-exchange membrane placed between them. An equal volume $\left(250 \mathrm{~cm}^{3}\right)$ of anolyte and catholyte is poured in their respective chamber after cell assembly. The anodic compartment is filled with the $\mathrm{HCl}$ solution, whereas the $\mathrm{Zn}(\mathrm{II}) / \mathrm{Fe}(\mathrm{II})$ mixture in $\mathrm{HCl}$ media is placed in the cathodic compartment. The electrodes are totally immersed in the solution and both cathode and anode, are symmetrically separated from the membrane surface.

For the two reactors, the anode and cathode are made of two cylindrical graphite bars with an effective area of $14.15 \mathrm{~cm}^{2}$. Experiments are performed at different applied currents, which ranged from -150 to $-700 \mathrm{~mA}$. The electrolysis experiments are controlled using an AutolabPGSTAT20 potentiostat/galvanostat. 
Samples are taken from the electrochemical reactor every $30 \mathrm{~min}$, and potential, current, cell voltage, $\mathrm{pH}$ and metal concentrations are recorded during the electrolysis. The determination of zinc is performed by atomic absorption spectrophotometry (AAS) on a Perkin-Elmer model Analyst 100 atomic absorption spectrophotometer using a zinc hollow cathode lamp at $213.9 \mathrm{~nm}$ wavelength, $0.7 \mathrm{~nm}$ spectral bandwidth and an operating current of $5 \mathrm{~mA}$. To measure iron concentration it is used the same equipment changing the $\mathrm{Zn}$ hollow lamp for a Fe hollow lamp, the wavelength used is $248.3 \mathrm{~nm}$, the applied operating current is $5 \mathrm{~mA}$ and the spectral bandwidth is $0.2 \mathrm{~nm}$.

All solutions are prepared using analytical grade reagents and distilled water. Electrolytes containing $\mathrm{ZnCl}_{2}$ and $\mathrm{FeCl}_{2}$ have a concentration value of $0.055 \mathrm{M}$ and $0.035 \mathrm{M}$, respectively. These values are similar to those present in the spent pickling baths. The $\mathrm{HCl}$ concentration is $0.1 \mathrm{M}$. All the experiments were performed at room temperature.

\section{3- Results and discussion}

\section{1- Synthetic solutions}

Initially, the electrolysis of synthetic solutions in absence of iron has been studied, and, afterwards the iron effect over zinc electrodeposition has been evaluated. Fig. 2 shows the variation of zinc ion concentration as a function of time at different applied current values for an electrolyte composed of $0.055 \mathrm{M} \mathrm{ZnCl}_{2}$ and $0.1 \mathrm{M} \mathrm{HCl}$. For the lowest cathodic current (-150 mA), the current density is low and the zinc concentration value remains practically constant. For intermediate current values (-300 and $-450 \mathrm{~mA})$, zinc 
concentration initially diminishes with time following a linear tendency because the applied current is lower than the limiting value. When the limiting current value is surpassed an exponentially decrease is obtained as observed for the most cathodic current value (-700 mA), where zinc concentration diminishes exponentially from the beginning of the experiment. For a given time value, as current is made more negative zinc becomes depleted from the solution faster and, consequently, the amount of zinc in solution is lower.

As in potentiostatic mode [7], a previous study of the iron effect on zinc electrodeposition is necessary in order to understand the behavior of the real sample. For this purpose, a synthetic solution with the same zinc and $\mathrm{HCl}$ concentrations as the previous one, and the same iron/zinc ratio as that present in the real sample $(0.055 \mathrm{M}$ $\mathrm{ZnCl}_{2}$ and $0.035 \mathrm{M} \mathrm{FeCl}_{2}$ in $0.1 \mathrm{M} \mathrm{HCl}$ ) is prepared. Fig. 3 shows the comparison of the zinc concentration evolution in the presence and absence of iron for the current values of -300 and $-700 \mathrm{~mA}$. For the current value of $-300 \mathrm{~mA}$, initially the rate of zinc depletion is slightly higher in the presence of iron but zinc redissolution appears at time values higher than $50 \mathrm{~min}$. The chlorine gas formed as a consequence of the $\mathrm{Cl}^{-}$ oxidation in the anode, along with iron promote the corrosion and the consequent redissolution of the metallic zinc deposit on the cathode surface $[10,11]$. For the current value of $-700 \mathrm{~mA}$, in presence of iron, the zinc reduction rate becomes negligible during the first steps of electrolysis, due to the iron and chlorine presence, that causes greater zinc redissolution [10-12]. For time values higher than $210 \mathrm{~min}$, zinc concentration begins to decrease although the zinc reduction rate is still low compared to that in the absence of iron. It is noteworthy to mention that the potential values obtained in the presence of iron were more cathodic than those obtained without iron, which indicates 
the enhancement of the HER process in the presence of iron $[13,14]$. Iron concentration was also measured and resulted invariable for all the current values under study. This fact may be related to the high acidity of the bulk solution and to the presence of zinc that could inhibit iron deposition [7].

The current efficiency of zinc deposition $(\phi)$ is greatly influenced by the presence of free chlorine dissolved in the electrolyte in conjunction with the presence of iron as can be observed in Fig 4, where the current efficiency of zinc deposition at -300 and -700 $\mathrm{mA}$ with and without iron is compared. The oxidation of the chloride ion present in solution to chlorine gas, promotes the chemical oxidation reaction of $\mathrm{Fe}^{2+}$ to $\mathrm{Fe}^{3+}$. The ferric iron competes with the $\mathrm{Zn}^{2+}$ ion for its reduction in the cathode lowering the current efficiency of the zinc reduction process. This effect was also observed by other authors $[10,11]$. The decrease in current efficiency observed in the presence of iron for both current values, is also associated with the enhancement of the HER process [13-15, 17], which also competes with zinc electrodeposition.

In general, the presence of iron in synthetic samples produces worse effects in galvanostatic mode in terms of zinc fractional conversion and current efficiency than in potentiostatic operation [7]. This is explained by the fact that in galvanostatic mode is only possible to control the global reaction rate, which makes impossible select the reaction of interest as occurs in potentiostatic mode.

In order to eliminate the adverse effects due to the combined presence of chlorine gas and iron when treating the real spent pickling solutions, the performance of the electrochemical reactor in the presence of an anionic exchange membrane is also 
evaluated. The use of an anion-exchange membrane between the anodic and the cathodic compartment allows the passage of electricity by means of the flow of $\mathrm{Cl}^{-}$ions towards the anodic compartment. On the other hand, the AEM also avoids the presence of chlorine in the catholyte which could reoxidize the ferrous iron to the ferric state [10, $11]$.

\section{2- Electrolysis of real spent pickling solutions}

In this section, the behavior of the electrochemical reactor in the presence and absence of the anionic exchange membrane when processing real spent pickling solutions is studied. The selected current values were the same to those used in point 3.1. when processing the synthetic sample for a better comparison of all data. Iron concentration was also measured for all the applied currents under study.

Fig. 5 represents the zinc concentration evolution with time in the undivided reactor for for a 1:50 diluted real sample. In this case, the zinc redissolution behavior is practically observed for all the applied current values. For the lowest cathodic current values, -150 and $-300 \mathrm{~mA}$, the zinc concentration initially diminishes and after a following increase, it remains practically constant. For the most cathodic current values, -450 and $-700 \mathrm{~mA}$, a great decrease in zinc concentration is previously observed beyond which zinc concentration starts to increase due to the zinc redissolution phenomenon. The redissolution of zinc was also observed in potentiostatic mode for all the potential values under study [7]. Evaluating both operating modes, it is inferred that zinc redissolution phenomenon is always present when treating the real spent pickling baths due to the effect of iron together with the dissolved chlorine. According to the work of 
O. Caldwell-Ralston [10], although most of the chlorine formed passes away as gas, it is soluble in the zinc chloride solution to some extent, and if this solution gets in contact with the cathode, corrosion takes place. If the electrolysis is free from iron, it is possible to deposit zinc with fair efficiency in the presence of a chlorine saturated solution, but when ferric iron is present serious redissolution sets in. It is therefore necessary to use membranes between the anode and cathode to trap most of the chlorine allowing little chlorine-bearing solution to diffuse into the vicinity of the cathode. In this context, the performance of a two-compartment batch electrochemical reactor separated by an anion-exchange membrane (AEM) has been evaluated in the present point.

Fig. 6 shows the conversion of zinc $\left(\mathrm{X}_{\mathrm{Zn}}\right)$ in the presence and absence of the anionexchange membrane (AEM) for two different values of applied current ( -300 and -700 $\mathrm{mA}$ ). For both values of applied current, zinc redissolution is practically negligible in the presence of the AEM. It is noteworthy to point out, that the divided reactor has a volume reactor of $250 \mathrm{ml}$ whereas that of the undivided reactor is $100 \mathrm{ml}$, in spite of this fact, the rate of zinc conversion is much better in the presence of the AEM since it reaches a $100 \%$ of zinc conversion at lower time values.

Fig. 7 presents the current efficiency of zinc deposition in the presence and absence of the anion-exchange membrane (AEM) for the two different values of applied current. As mentioned previously, the current efficiency of zinc deposition is greatly affected by the presence of free chlorine dissolved in the electrolyte. For both applied currents in the absence of the AEM, the chlorine formed in the anode can reoxidize the ferrous iron to the undesirable ferric state. This latter species competes with $\mathrm{Zn}^{2+}$ for its reduction in the cathode consuming high amounts of energy, which is reflected by current efficiency 
values lower than $3 \%$ at the final steps of the electrolysis. However, when the AEM is present, the presence of chlorine in the cathodic compartment is minimized and higher values of current efficiency are reached in both cases. It is worth to mention that the zinc deposition in chloride medium is always accompanied by the evolution of hydrogen from the initial stages. This fact explains the relatively low values of current efficiencies reached for all the experimental conditions, especially, at $-700 \mathrm{~mA}$, since although the AEM blocks the passage of chlorine to the catholyte, the amount of hydrogen formed in the cathode surface is excessive at this high cathodic current. The lower values of $\phi$ observed at high electrolysis times are explained by the zinc depletion and the beginning of the secondary reactions.

As mentioned above, if the AEM is present, the dissolved chlorine near the cathode is minimized which facilitates the hydrogen evolution reaction [10] and the consequent local $\mathrm{pH}$ increase of the cathode. This local $\mathrm{pH}$ increase in conjunction with the zinc depletion facilitates the iron deposition as shown in Fig. 8 for the applied currents values of -300 and $-700 \mathrm{~mA}$ in the presence of the AEM. In this case, the average iron conversion for both applied currents is around $90 \%$. The iron deposition in the presence of the AEM for both applied current under study is also reflected by the electrode potential evolution observed in Fig. 9.

Because the galvanostatic operation corresponds to an imposed global reaction rate, the electrode potential (E) and the cell voltage (U) change with time as can be observed in Fig. 9 at -300 and $-700 \mathrm{~mA}$. For both applied currents, as a consequence of the electrode activation and the decrease of the electrode overvoltage due to zinc deposition, the cell voltage initially decreases until a minimum value. Afterwards, the cell voltage increases 
sharply because of the decrease of the electrolyte conductivity caused by the removal of zinc and iron from solution, which inevitably introduces an ohmic drop.

In relation to the electrode potential for both applied currents, initially, is very cathodic (between -2 and $-2.5 \mathrm{~V}$ ) because the resistance of the electrode to zinc electrodeposition is very high. As zinc is depleted from solution, the iron deposition starts as was previously observed in Fig. 8. This fact is reflected by the codeposition of both species on the graphite electrode. The deposition of the zinc-iron alloy takes place at potential values more similar to those obtained for the zinc species, and E remains practically constant. For an applied current of $-300 \mathrm{~mA}$ and once zinc and iron are depleted from solution (around 200 sec.), the electrode potential moves to more cathodic values corresponding to the hydrogen evolution reaction. However, in the case of an applied current of $-700 \mathrm{~mA}$, when zinc is completely removed from solution (around 100 seconds), there is still some iron species remaining in solution, which contributes to the shift of E to less cathodic values, as iron deposition process at more positive values [7]. Finally, E decreases to values close to the hydrogen evolution reaction zone. The evolution of E observed in Fig. 9 is consistent with the anomalous co-deposition theory. The electrodeposition of zinc alloys with the eight group metals (Ni, Co and $\mathrm{Fe}$ ) is classified as anomalous co-deposition, according to the Brenner definition [18-20], because the less noble metal deposits preferentially on the cathode with respect to the nobler one. In our case, when zinc is electroplated from an acidic electrolyte containing an iron group element, the less noble zinc is most often deposited preferentially. A model initially proposed by Dahms et al [21] suggests that the formation of an intermediate metal hydroxide closely adjacent to the cathode surface inhibits the deposition of the more noble metal ion in the electrolyte. The metal hydroxide is 
believed to form due to local increase in $\mathrm{pH}$ at the substrate surface during electrodeposition caused by the high overpotential for reduction of hydrogen ions when the substrate is polarized cathodically. The following factors have found to affect the anomalous co-deposition mechanism: cathodic current density, electrolyte $\mathrm{pH}$, agitation rate and chloride content in the plating electrolyte [22].

The effect of the applied current on the zinc fractional conversion $\left(\mathrm{X}_{\mathrm{Zn}}\right)$, current efficiency $(\phi)$, space-time yield $(\eta)$ and energy consumption $\left(E_{s}\right)$ when the AEM is present is represented in Figs. 10-13, respectively. The evolution of the zinc fractional conversion in the two-compartment electrochemical reactor is shown in Fig. 10. It can be observed that $\mathrm{X}_{\mathrm{Zn}}$ increases with increasing both electrolysis time and current. When the applied current is less cathodic than $-700 \mathrm{~mA}$, the zinc fractional conversion increases linearly with time since, initially, the applied current is lower than the limiting value. After a certain time, the applied current becomes equal to or greater than the limiting current, and the zinc fractional conversion increases more slowly with time following an exponential tendency. For the lowest cathodic current value of $-150 \mathrm{~mA}$, the electrolysis time was too short to reach the limiting current conditions and this fact explains the lack of exponential tendency. It is noteworthy to mention that at this low applied current, the zinc fractional conversion was negligible in the absence of the AEM. On the other hand, for very cathodic conditions $(-700 \mathrm{~mA})$ since the applied current is initially greater than the limiting value, the conversion increase with time follows an exponential tendency from the beginning of the experiments.

As shown in Fig. 11, in general, $\phi$ decreases with increasing the applied current due to the significant extent of secondary reactions. Since the hydrogen evolution is present 
from the initial steps of the electrolysis, the current efficiency never reaches a $100 \%$ even though presents considerably high values especially for the lowest applied currents (between 50 and 60\%). For a given value of applied current, $\phi$ is initially very low due to the resistance of the cathode to zinc deposition. As the electrode becomes covered with zinc, current efficiency increases up to a maximum value. Finally, $\phi$ decreases exponentially with time because at this point the applied current is greater than the limiting current, zinc concentration drops and other secondary reactions such as hydrogen evolution and iron deposition become dominant.

Fig. 12 shows the evolution of the space-time yield with time for the different applied currents. In general, the space-time yield increase over the initial period can be attributed to the nucleation of zinc onto the graphite electrode that causes a decrease in the electrode resistance for the deposition of zinc. Then, the space-time yield decreases slowly with time due to the removal of zinc from the solution and similar values are reached for the different applied currents at the end of the electrolysis since a $100 \%$ of zinc is recovered for every value of current.

The effect of the applied current on the evolution of the specific energy consumption with time is shown in Fig. 13. The increase of $\mathrm{E}_{\mathrm{s}}$ with the applied current can be attributed to the decrease in current efficiency because of the onset of the hydrogen evolution. For applied currents ranging from -150 to $-450 \mathrm{~mA}$, since they are initially lower than the limiting current, $\mathrm{E}_{\mathrm{s}}$ keeps practically constant in a relatively low value up to a critical time beyond which, the hydrogen evolution is very important, and consequently, the energy consumed is increased. At -700 mA the energy consumed 
practically increases continuously with time because the applied current is always higher than the limiting current.

As studied in potentiostatic mode, in order to compare the performance of the electrochemical reactor for the different applied currents, the time $\left(t_{100}\right)$ at which a $100 \%$ zinc fractional conversion is reached, assuming a current efficiency of $100 \%$, has been determined. In galvanostatic operation, $\mathrm{t}_{100}$ can be calculated from the following equation [23]:

$t_{100}=\frac{n F V C_{0}}{I}$

where $t_{100}$ represents the time when the charge passed through the reactor corresponds to the stoichiometric value. For this time value, the four figures of merit, $X_{\mathrm{Zn}}, \phi, \eta$ and $\mathrm{E}_{\mathrm{s}}$, have been calculated and are summarized in Tables 1 and 2 for the divided and undivided electrochemical reactor, respectively.

In both tables, $\mathrm{t}_{100}$ decreases as the current is shifted towards more cathodic values as predicted by Eq. (1). The values of $t_{100}$ presented in Table 1 are higher than those of Table 2 because the higher volume of the cathodic compartment of the twocompartment reactor $(250 \mathrm{ml})$ in comparison to that of the one-compartment reactor $(100 \mathrm{ml})$ requires higher times values for zinc depletion.

Comparing the data presented in these tables it is inferred that the presence of the anionexchange membrane gives better values in terms of zinc conversion rate, current efficiency and space-time yield. On the other hand, the energy consumed in the 
presence of the AEM presents slightly higher values than those obtained in the one compartment reactor (Table 2), in spite of the fact that the cell potential is about 6 times higher in the divided reactor. The higher values of zinc conversion and current efficiency presented in Table 1 are related to the minimization of the presence of chlorine in the cathodic compartment which, together with iron, is responsible for the zinc redissolution and the waste of energy in secondary reactions. Regarding with the data presented in Table 1, the applied current of $-700 \mathrm{~mA}$ may be selected as the optimum since the conversion, current efficiency and space-time yield are relatively high whereas the consumption of energy is moderate. Moreover, at this high cathodic current the zinc is recovered at lower time values. 


\section{4- Conclusions}

A two-compartment electrochemical reactor in galvanostatic mode was used to recover zinc from the spent pickling solutions coming from the hot dip galvanizing industry. These solutions mainly contain $\mathrm{ZnCl}_{2}$ and $\mathrm{FeCl}_{2}$ in aqueous $\mathrm{HCl}$ media. The different figures of merit were calculated in order to compare the behavior of the reactor in the presence and absence of the anion-exchange membrane and to select the best conditions for zinc recovery.

In the absence of iron in solution, as the current value was shifted towards more negative values, zinc fractional conversion increased because of the increase in the zinc reduction rate. However, the increase in current values makes current efficiency decrease due to the hydrogen-reduction side reaction, which causes an increment in the specific energy consumption. In the absence of the AEM, even though iron deposition does not take place for any experimental conditions under study, its presence in synthetic $\mathrm{Zn} / \mathrm{Fe}$ solutions led to a decrease in current efficiency associated with the reverse redox $\mathrm{Fe}^{2+} / \mathrm{Fe}^{3+}$ system and to the enhancement of the HER.

If the values of the zinc fractional conversion and current efficiency are compared, it is inferred that the presence of the anion-exchange membrane avoids the adverse effects of the combined presence of chlorine and iron. In this case, the zinc redissolution is eliminated which enables zinc conversion values close to $100 \%$ for all the experimental conditions together with higher current efficiencies as the consumption of current by the system $\mathrm{Fe}^{2+} / \mathrm{Fe}^{3+}$ is diminished. The applied current of $-700 \mathrm{~mA}$ is considered to be 
optimal from the viewpoint of zinc recovery present in the spent pickling baths since relatively high values of fractional conversional and current efficiency are obtained.

\section{Acknowledgements}

Authors want to express their gratitude to the Universidad Politecnica de Valencia for the economic support in the project reference PAID-06-08, and to the Generalitat Valenciana for the financing of the project reference GV/2010/029. 


\section{References}

[1] U. Kerney, Treatment of spent pickling acids from hot dip galvanizing, Resour. Conserv. Recy. 10 (1994) 145-151.

[2] C. Stocks, J. Wood, S. Guy, Minimization and recycling of spent acid wastes from galvanizing plants, Resour. Conserv. Recy. 44 (2005) 153-166.

[3] G. Csicsovszki, Tamás Kékesi, Tamás I.Török. Selective recovery of Zn and Fe from spent pickling solutions by the combination of anion exchange and membrane electrowinning techniques, Hydrometallurgy 2005; 77:19-28.

[4] L. Muresan, G. Maurin, L. Oniciu, S. Avram, Effects of additives on zinc electrowinning from industrial waste products, Hydrometallurgy 40 (1996) 335-342.

[5] A. Carrera, E. Bringas, M. F. S. Roman, I. Ortiz, Selective membrane alternative to the recovery of zinc from hot-dip galvanizing effluents, J. Membr. Sci. 326 (2009) 672680.

[6] A. Recéndiz, I. González, J.L. Nava, Current efficiency studies of the zinc electrowinning process on aluminum rotating cylinder electrode (RCE) in sulphuric acid medium: Influence of different additives, Electrochim. Acta 52 (2007) 6880-6887.

[7] J. Carrillo- Abad, M. García-Gabaldón, E. Ortega, V. Pérez-Herranz, Electrochemical recovery of zinc from the spent pickling baths coming from the hot dip galvanizing industry. Potentiostatic operation, Sep. Purif. Technol. 81 (2011) 200-207.

[8] P. Díaz-Arista, O.R. Mattos, O.E. Barcia, F.J. Fabri Miranda, ZnFe anomalous electrodeposition: stationaries and local pH measurements, Electrochim. Acta 47 (2002) 4091-4100. 
[9] M. García-Gabaldón, V. Pérez-Herranz, J. García-Anton, J.L. Guinon, Electrochemical recovery of tin from the activating solutions of the electroless plating of polymers: Galvanostatic operation, Sep. Purif. Technol. 51 (2006) 143-149.

[10] O. Caldwell-Ralston, Electrolytic deposition and hydrometallurgy of zinc, McGraw-Hill Book Company, Inc., New York, 1921.

[11] B.K.Thomas, D.J.Fray, Electrolysis of zinc chloride solutions at high current densities, Trans. Instn. Min. Metall. (Sect. C: Mineral Process. Extr. Metall.) 91 (1982) C105-C111.

[12] F. Simescu, H. Idrissi, Corrosion behaviour in alkaline medium of zinc phosphate coated steel obtained by cathodic electrochemical treatment, Corr. Sci. 51 (2009) 833840.

[13] K. Saber, C.C. Koch, P.S. Fedkiw, Pulse current electrodeposition of nanocrystalline zinc, Mater. Sci. Eng. A 341 (2003) 174-181.

[14] L. Muresan, G. Maurin, L. Oniciu, D. Gaga, Influence of metallic impurities on zinc electrowinning from sulphate electrolyte, Hydrometallurgy 43 (1996) 345-354.

[15] A.E. Saba, A.E. Elsherief, Continuous electrowinning of zinc, Hydrometallurgy 54 (2000) 91-106.

[16] P. Gu, R. Pascual, M. Shirkhanzadeh, S. Saimoto, J. D. Scott, The influence of Al substrate intermetallic precipitates on zinc electrodeposition, Hydrometallurgy 37 (1995) 267-281.

[17] E. Gómez, X. Alcobe, E. Vallés, Characterisation of zinc+cobalt alloy phases obtained by electrodeposition, J. Electroanal. Chem. 505 (2001) 54-61. 
[18] G. Roventi, R. Fratesi, R.A.D. Guardia, G. Barucca, Normal and anomalous codeposition of Zn-Ni alloys from chloride bath, J. Appl. Electrochem. 30 (1999) 173179.

[19] Z. Zhang, W.H. Leng, H.B. Shao, J.Q. Zhang, J.M. Wang, C.N. Cao, Study on the behavior of Zn-Fe alloy electroplating, J. Electroanal. Chem. 516 (2001) 127-130.

[20] E. Gómez, E. Vallés, Electrodeposition of zinc + cobalt alloys: initiations and development of anomalous co-deposition, J. Electroanal. Chem. 421 (1997) 157-163.

[21] H. Dahms, I.M. Croll, The Anomalous Codeposition of Iron-Nickel Alloys, J. Electrochem. Soc. 112 (1965) 771-775.

[22] J.D. Jensen, D. R. Gabe, G. D. Wilcox, The practical realization of zinc-iron CMA coatings, Surf. Coat. Tech. 105 (1998) 240-250.

[23] M. García-Gabaldón, V. Pérez-Herranz, J. García-Anton, J.L. Guinon, Electrochemical recovery of tin and palladium from the activating solutions of the electroless plating of polymers: Potentiostatic operation, Sep. Purif. Technol. 45 (2005) 183-191. 


\section{Figures and Tables}

Fig. 1: Schematic diagram of the two-compartment electrochemical reactor.

Fig. 2: Evolution of zinc concentration vs. time as a function of the applied current. $\left[\mathrm{ZnCl}_{2}\right]_{0}=0.055 \mathrm{M},[\mathrm{HCl}]_{0}=0.1 \mathrm{M}$.

Fig. 3: Evolution of zinc concentration vs. time as a function of the applied current. $\left[\mathrm{ZnCl}_{2}\right]_{0}=0.055 \mathrm{M},\left[\mathrm{FeCl}_{2}\right]_{0}=0.035 \mathrm{M},[\mathrm{HCl}]_{0}=0.1 \mathrm{M}$.

Fig. 4: Evolution of current efficiency vs. time as a function of the applied current. $\left[\mathrm{ZnCl}_{2}\right]_{0}=0.055 \mathrm{M},\left[\mathrm{FeCl}_{2}\right]_{0}=0.035 \mathrm{M},[\mathrm{HCl}]_{0}=0.1 \mathrm{M}$.

Fig. 5: Evolution of zinc concentration vs. time as a function of the applied current. 1:50 diluted real sample.

Fig. 6: Evolution of zinc conversion vs. time as a function of the applied current in the presence and absence of the AEM. 1:50 diluted real sample.

Fig. 7: Evolution of current efficiency vs. time as a function of the applied current in the presence and absence of the AEM. 1:50 diluted real sample.

Fig. 8: Evolution of zinc and iron concentration vs. time as a function of the applied current in the presence of the AEM. 1:50 diluted real sample

Fig. 9: Evolution of the electrode and cell potential vs. time as a function of the applied current in the presence of the AEM. 1:50 diluted real sample

Fig. 10: Evolution of zinc conversion vs. time as a function of the applied current in the presence of the AEM. 1:50 diluted real sample.

Fig. 11: Evolution of zinc current efficiency vs. time as a function of the applied current in the presence of the AEM. 1:50 diluted real sample.

Fig. 12: Evolution of zinc space-time yield vs. time as a function of the applied current in the presence of the AEM. 1:50 diluted real sample. 
Fig. 13: Energy consumption of zinc vs. time as a function of the applied current in the presence of the AEM. 1:50 diluted real sample.

Table 1. Figures of merit for the electrochemical recovery of zinc corresponding to $t_{100}$ for a 1:50 diluted real sample in the presence of the AEM.

Table 2. Figures of merit for the electrochemical recovery of zinc corresponding to $t_{100}$ for a 1:50 diluted real sample. 


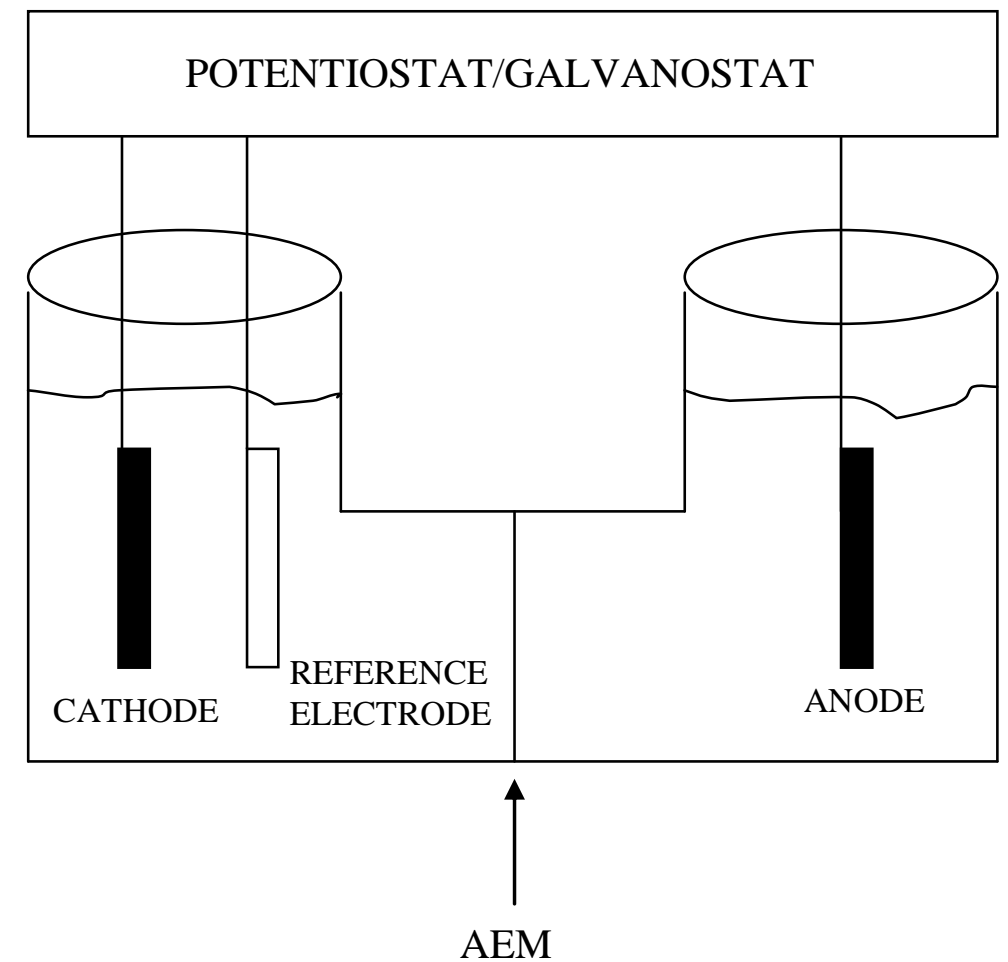

Fig. 1: Schematic diagram of the two-compartment electrochemical reactor. 


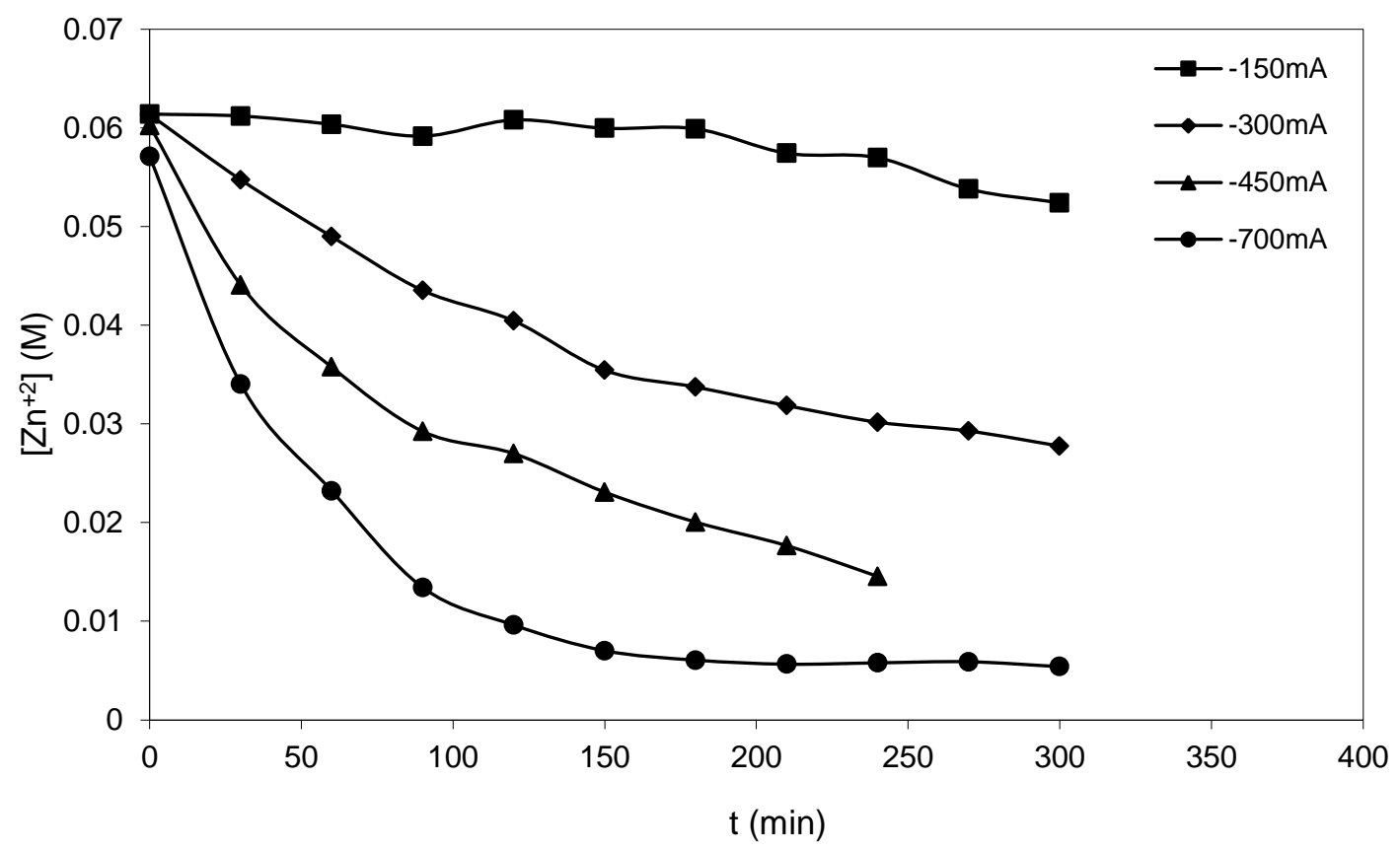

Fig. 2: Evolution of zinc concentration vs. time as a function of the applied current. $\left[\mathrm{ZnCl}_{2}\right]_{0}=0.055 \mathrm{M},[\mathrm{HCl}]_{0}=0.1 \mathrm{M}$. 


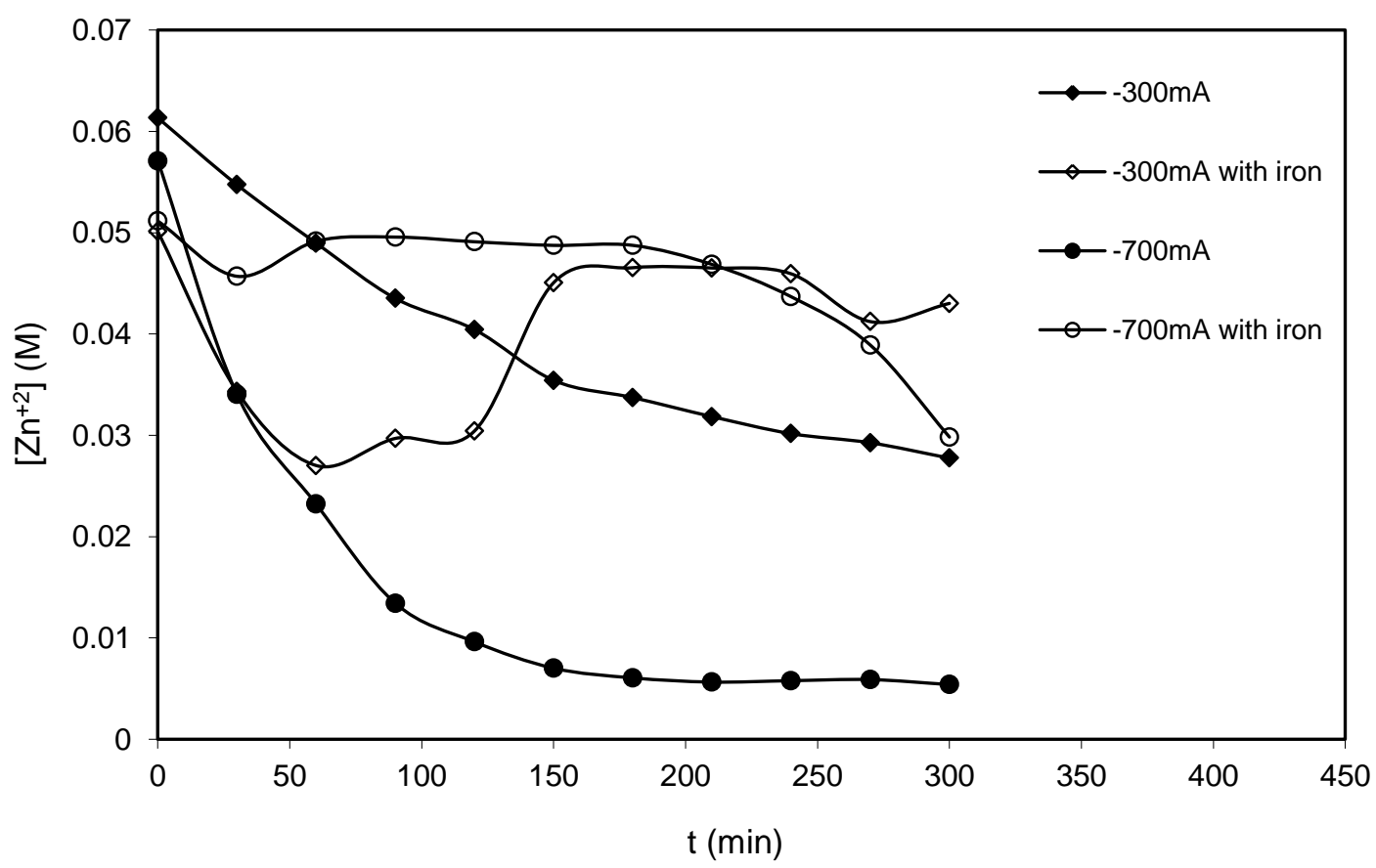

Fig. 3: Evolution of zinc concentration vs. time as a function of the applied current. $\left[\mathrm{ZnCl}_{2}\right]_{0}=0.055 \mathrm{M},\left[\mathrm{FeCl}_{2}\right]_{0}=0.035 \mathrm{M},[\mathrm{HCl}]_{0}=0.1 \mathrm{M}$. 


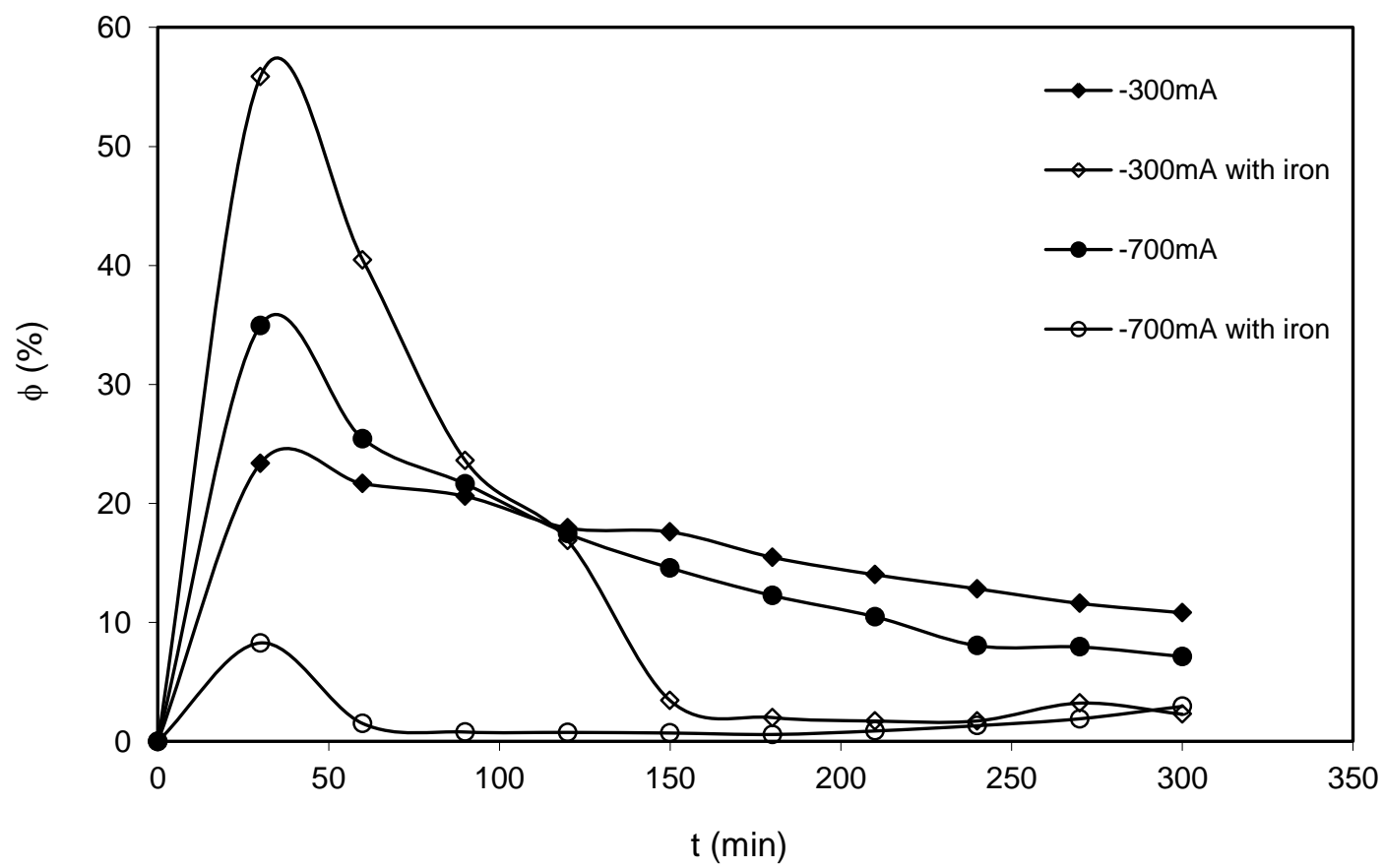

Fig. 4: Evolution of current efficiency vs. time as a function of the applied current. $\left[\mathrm{ZnCl}_{2}\right]_{0}=0.055 \mathrm{M},\left[\mathrm{FeCl}_{2}\right]_{0}=0.035 \mathrm{M},[\mathrm{HCl}]_{0}=0.1 \mathrm{M}$. 


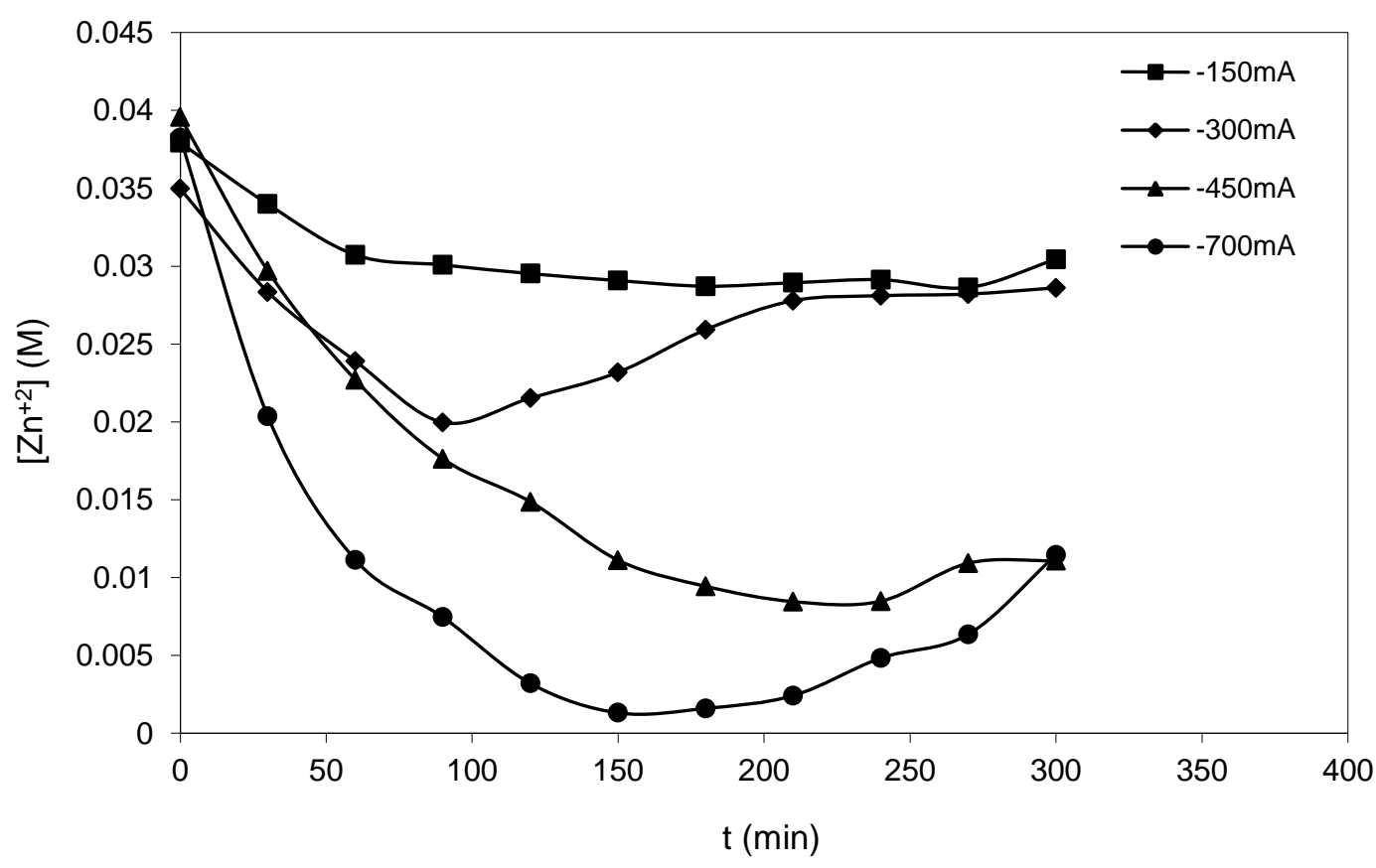

Fig. 5: Evolution of zinc concentration vs. time as a function of the applied current. 1:50 diluted real sample. 


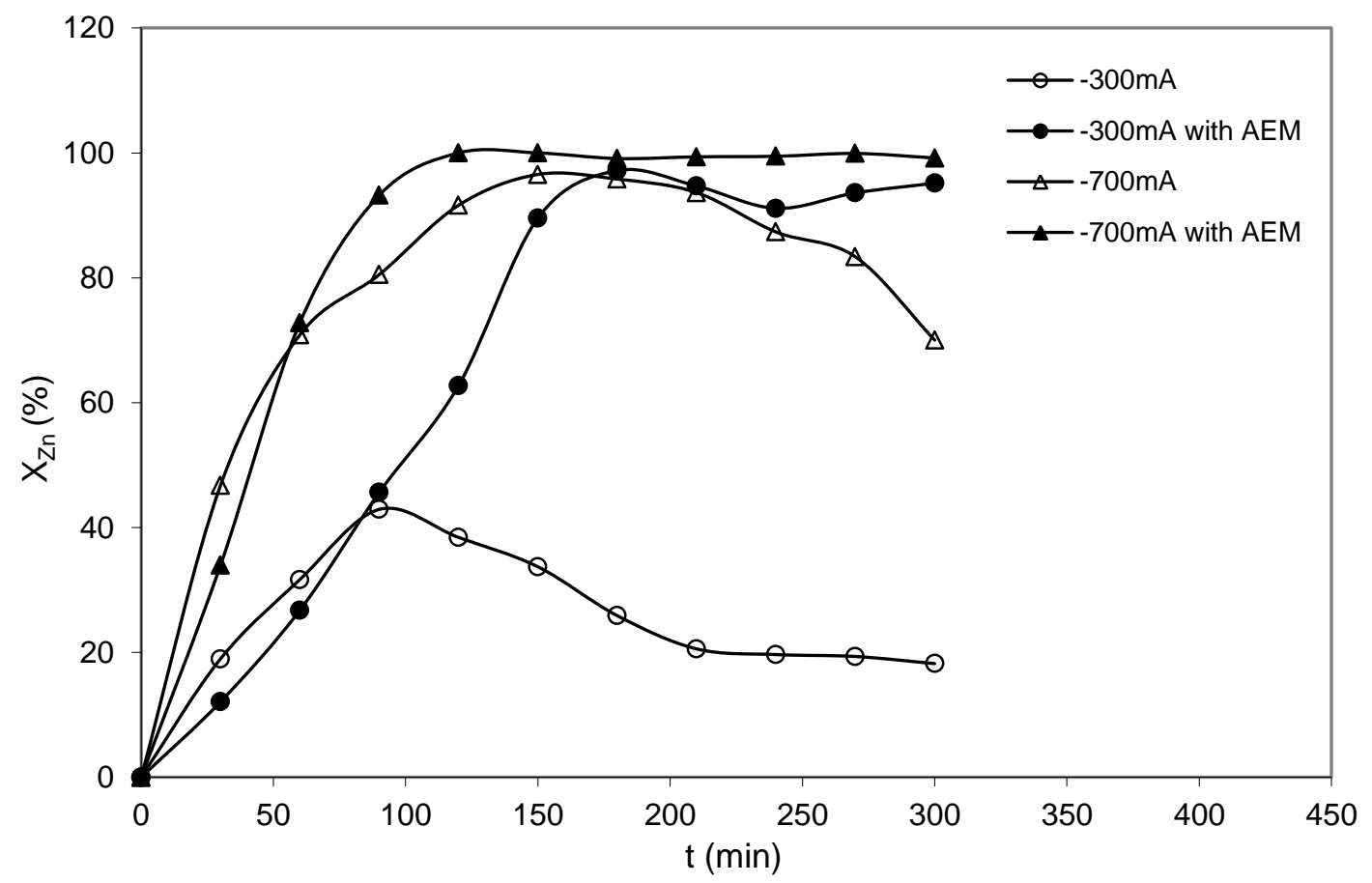

Fig. 6: Evolution of zinc conversion vs. time as a function of the applied current in the presence and absence of the AEM. 1:50 diluted real sample. 


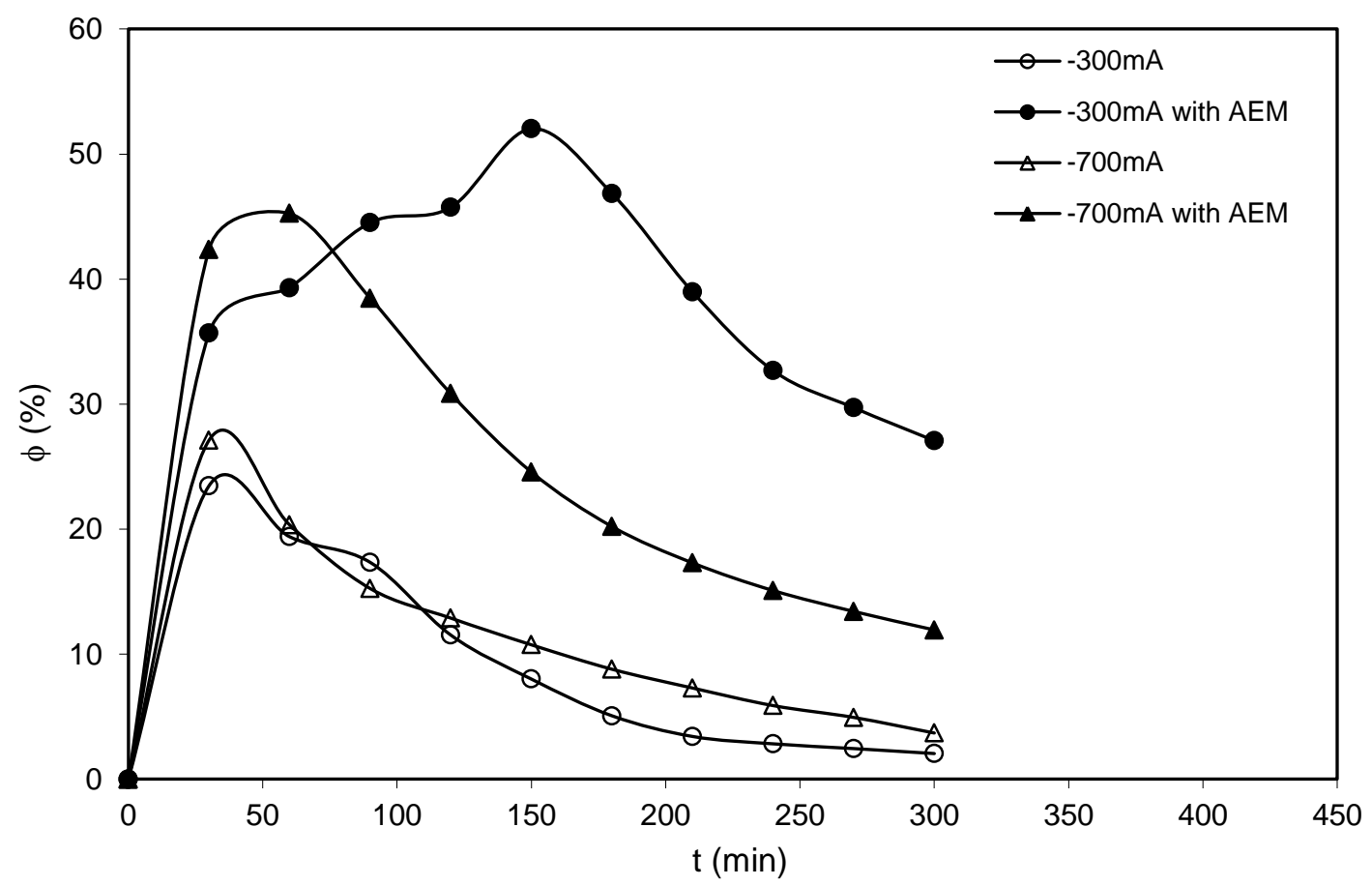

Fig. 7: Evolution of current efficiency vs. time as a function of the applied current in the presence and absence of the AEM. 1:50 diluted real sample. 


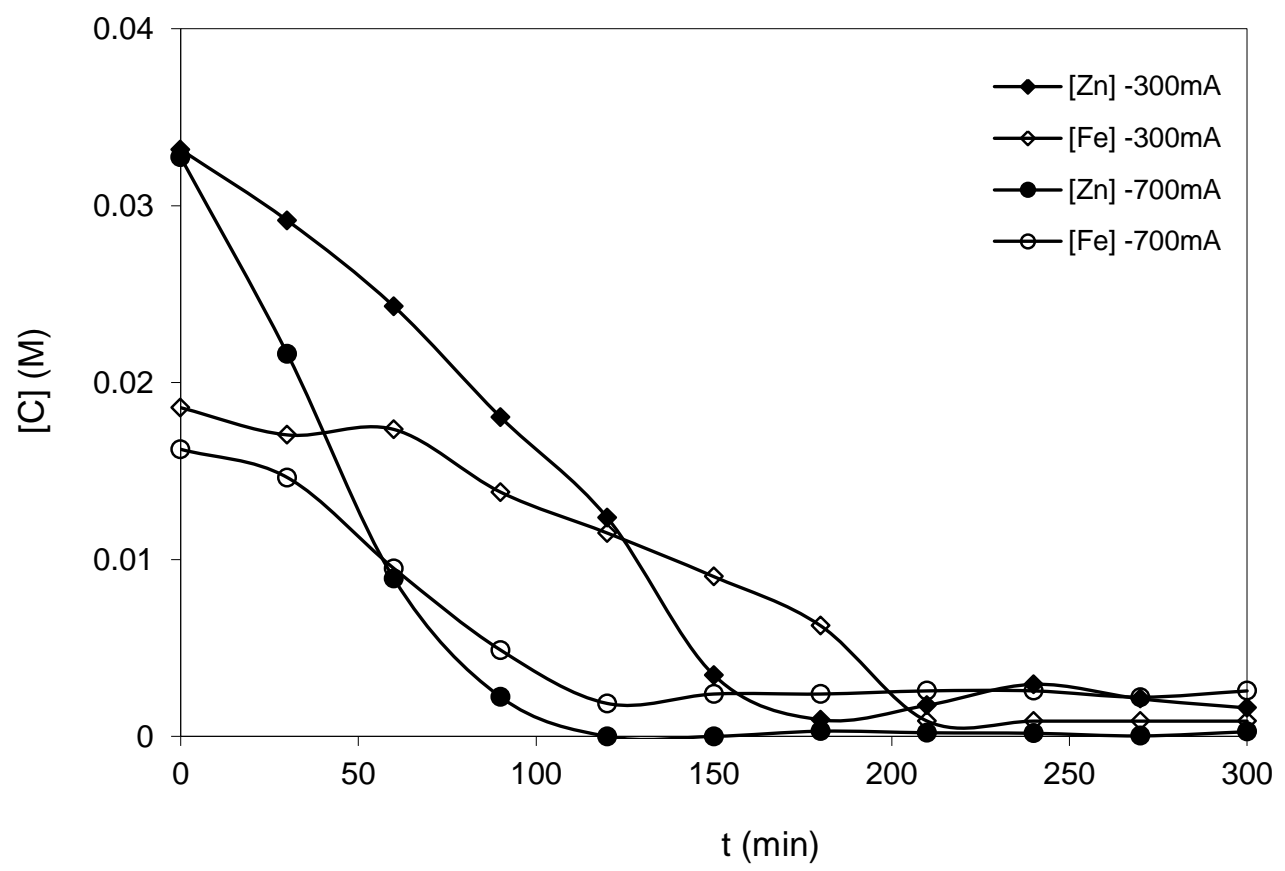

Fig. 8: Evolution of zinc and iron concentration vs. time as a function of the applied current in the presence of the AEM. 1:50 diluted real sample 


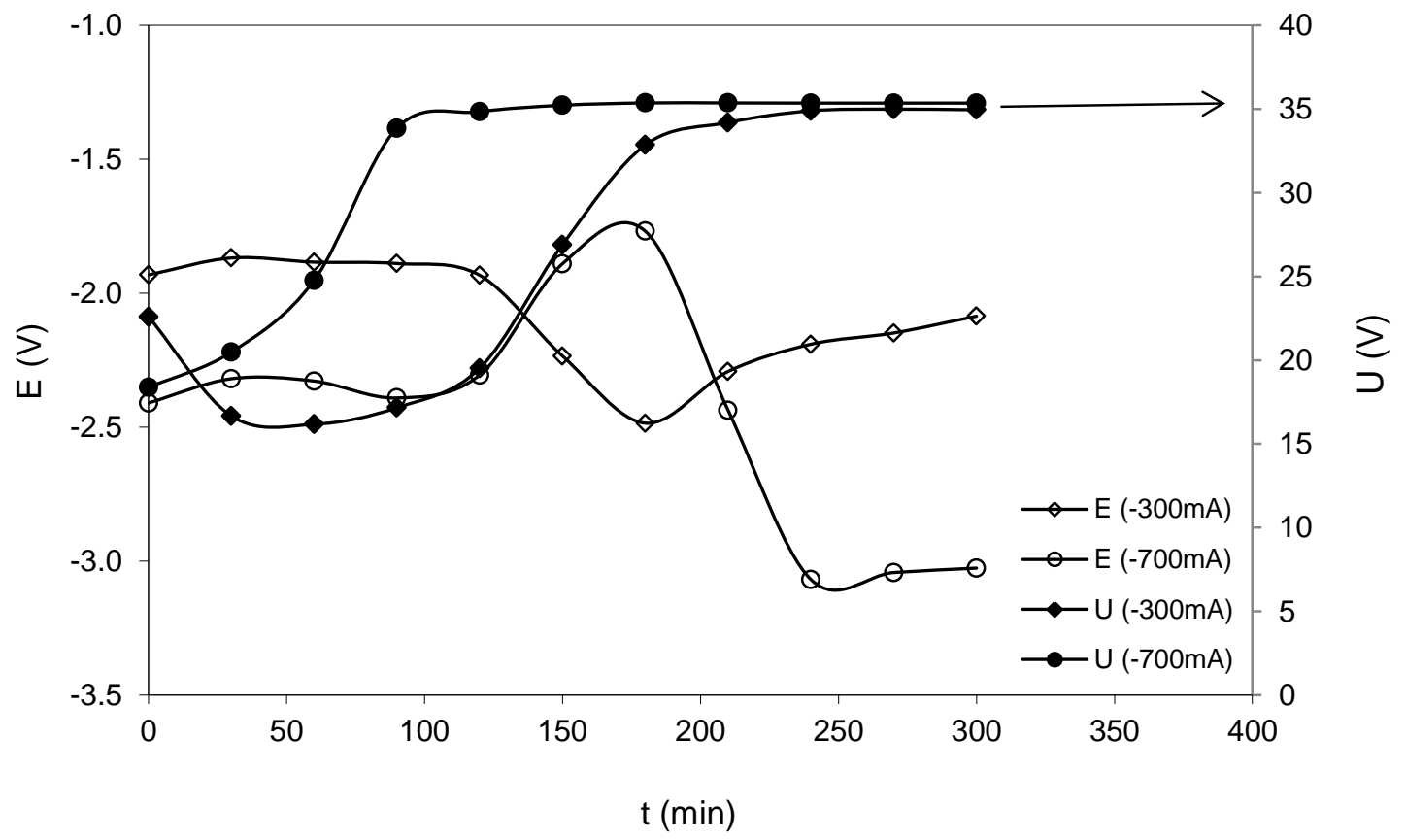

Fig. 9: Evolution of the electrode and cell potential vs. time as a function of the applied current in the presence of the AEM. 1:50 diluted real sample 


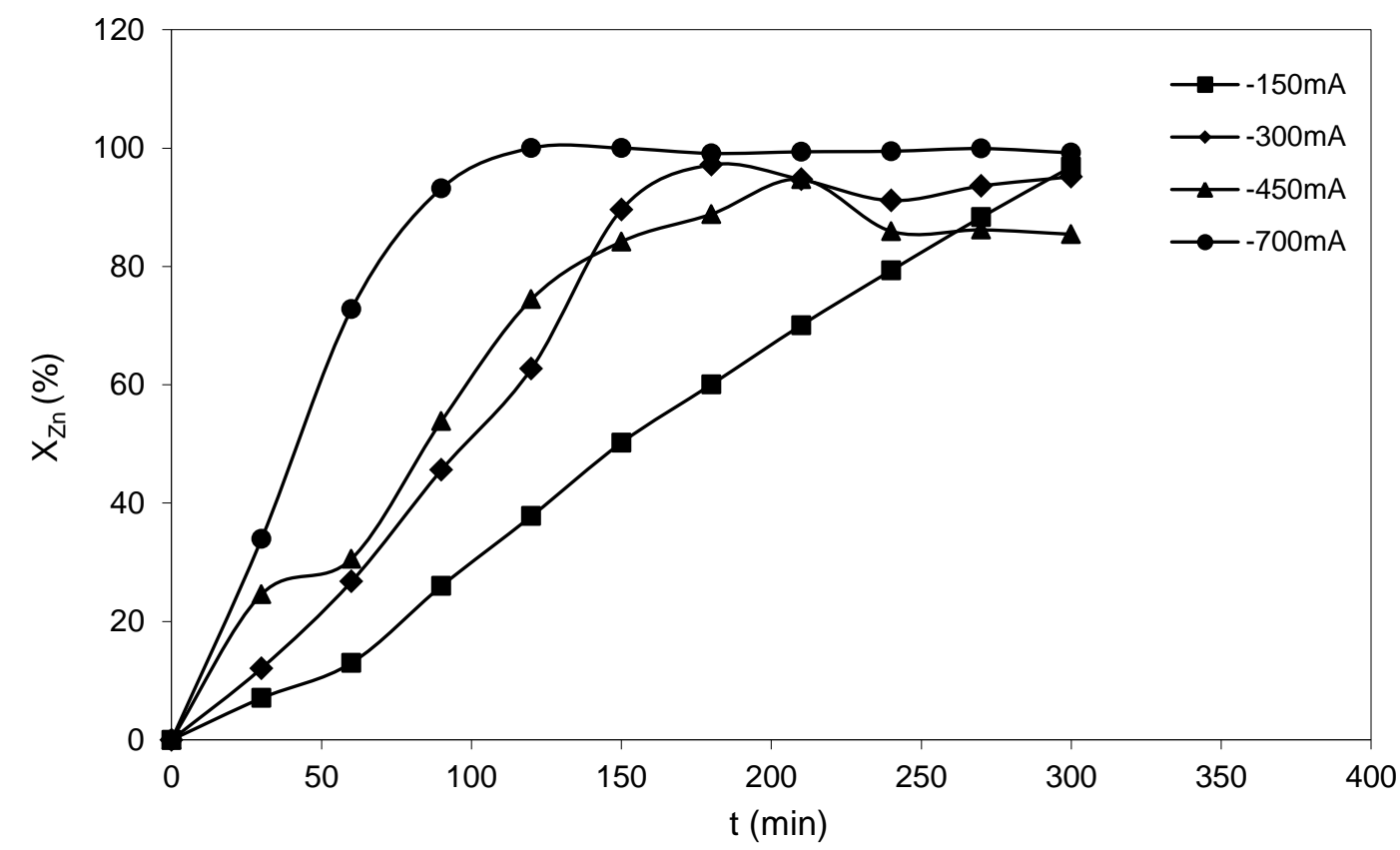

Fig. 10: Evolution of zinc conversion vs. time as a function of the applied current in the presence of the AEM. 1:50 diluted real sample. 


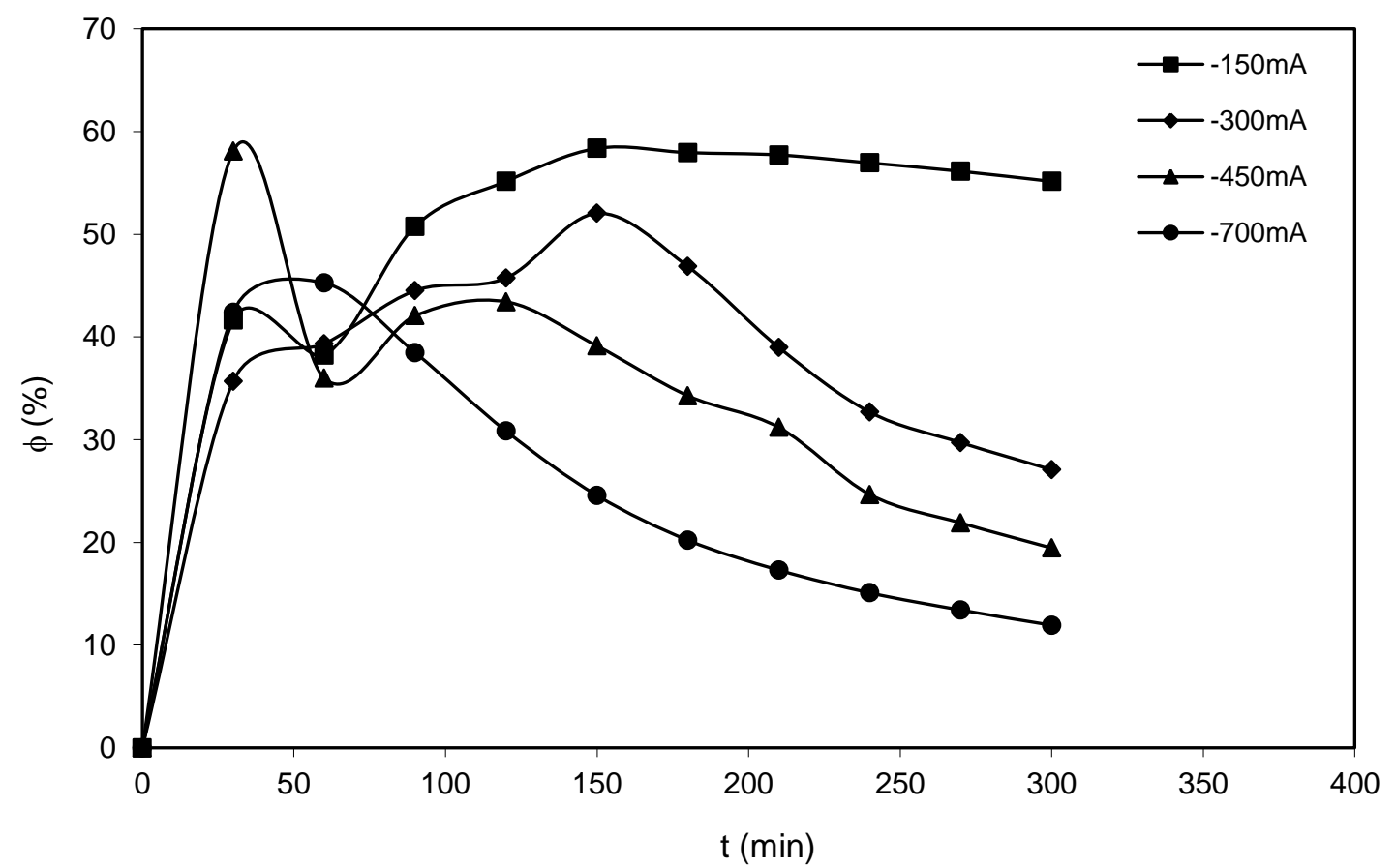

Fig. 11: Evolution of zinc current efficiency vs. time as a function of the applied current in the presence of the AEM. 1:50 diluted real sample. 


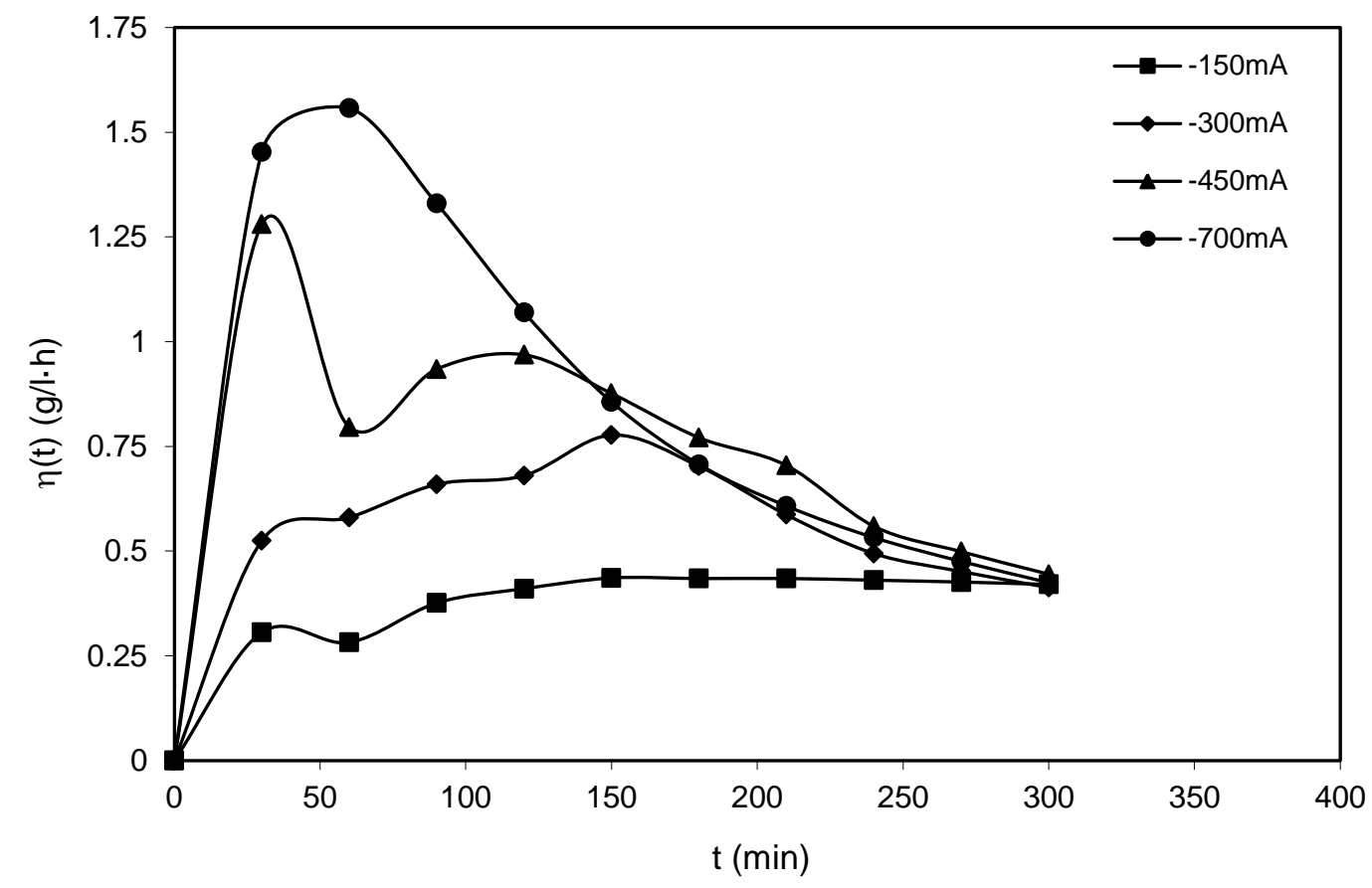

Fig. 12: Evolution of zinc space-time yield vs. time as a function of the applied current in the presence of the AEM. 1:50 diluted real sample. 


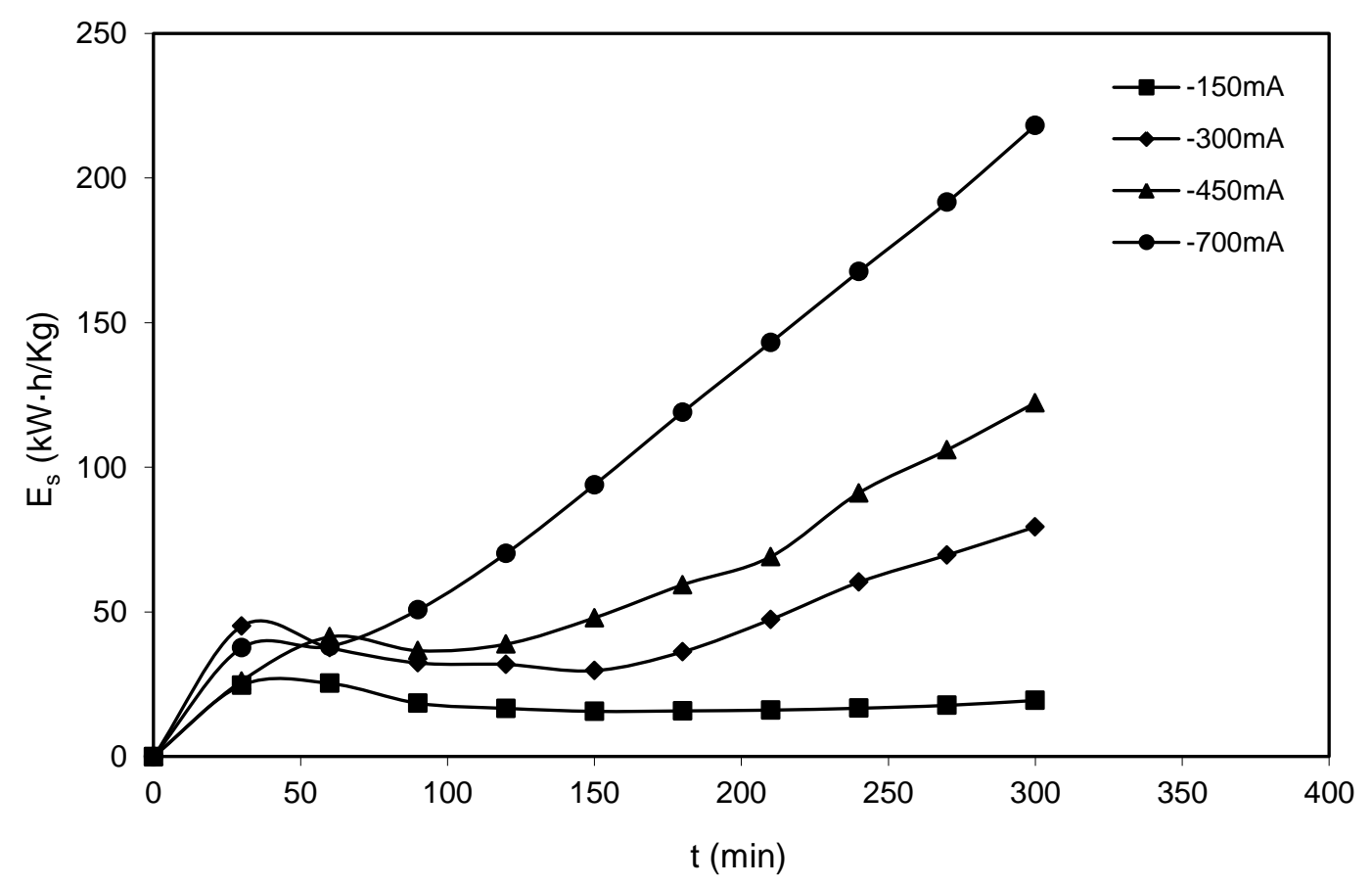

Fig. 13: Energy consumption of zinc vs. time as a function of the applied current in the presence of the AEM. 1:50 diluted real sample. 
Table 1. Figures of merit for the electrochemical recovery of zinc corresponding to $t_{100}$ for a 1:50 diluted real sample in the presence of the AEM.

\begin{tabular}{|c|c|c|c|c|c|}
\hline $\mathbf{I}(\mathbf{m A})$ & $\mathbf{t}_{\mathbf{1 0 0}}(\mathbf{m i n})$ & $\mathbf{X}_{\mathbf{Z n}}(\boldsymbol{\%})$ & $\boldsymbol{\Phi}(\mathbf{\%})$ & $\boldsymbol{\eta}\left(\mathbf{g} \cdot \mathbf{I}^{-\mathbf{1}} \cdot \mathbf{h}-{ }^{\mathbf{1}}\right)$ & $\mathbf{E}_{\mathbf{s}}\left(\mathbf{k W} \cdot \mathbf{h} \cdot \mathbf{k g}^{-\mathbf{1}}\right)$ \\
\hline-150 & 178 & 59.4 & 57.97 & 0.43 & 15.80 \\
\hline-300 & 97 & 50.0 & 44.89 & 0.67 & 32.24 \\
\hline-450 & 71 & 39.2 & 38.86 & 0.86 & 22.45 \\
\hline-700 & 47 & 55.3 & 44.45 & 1.53 & 38.57 \\
\hline
\end{tabular}

Table 2. Figures of merit for the electrochemical recovery of zinc corresponding to $t_{100}$ for a 1:50 diluted real sample.

\begin{tabular}{|c|c|c|c|c|c|}
\hline $\mathbf{I}(\mathbf{m A})$ & $\mathbf{t}_{\mathbf{1 0 0}}(\mathbf{m i n})$ & $\mathbf{X}_{\mathbf{Z n}}(\boldsymbol{\%})$ & $\boldsymbol{\Phi}(\mathbf{\%})$ & $\boldsymbol{\eta}\left(\mathbf{g}^{\mathbf{l}^{-\mathbf{1}} \cdot \mathbf{h}-} \mathbf{-}^{\mathbf{1}}\right)$ & $\mathbf{E}_{\mathbf{s}}\left(\mathbf{k W} \cdot \mathbf{h} \cdot \mathbf{k g}^{-\mathbf{1}}\right)$ \\
\hline-150 & 81 & 20.0 & 19.04 & 0.36 & 16.10 \\
\hline-300 & 38 & 22.1 & 21.86 & 0.81 & 21.86 \\
\hline-450 & 28 & 23.5 & 23.33 & 1.29 & 23.11 \\
\hline-700 & 18 & 27.4 & 27.22 & 2.34 & 20.84 \\
\hline
\end{tabular}

